\title{
Mango mistletoe Dendrophthoe pentandra leaf extract acts synergistically with 5-Fluorouracil to induce apoptosis and increase p21 expression in human cervical adenocarcinoma HeLa cells by reducing survivin expression
}

\author{
Agustina Tri Endharti ${ }^{1,2^{*}}$, Eni Sulastri ${ }^{3}$, Rabiah Umanailo $^{3}$, Yunialce ${ }^{3}$, Tatit Nurseta ${ }^{4}$, Kusworini Handono ${ }^{5}$ \\ ${ }^{1}$ Department of Parasitology, Faculty of Medicine, Brawijaya University, Malang, Indonesia. \\ ${ }^{2}$ Biomedical Central Laboratory, Faculty of Medicine, Brawijaya University, Indonesia. \\ ${ }^{3}$ Master Program in Midwifery, Faculty of Medicine, Brawijaya University, Malang, Indonesia. \\ ${ }^{4}$ Departement of Gynecology and Onco-gynecology Saiful Anwar Hospital, Medical Faculty, University of Brawijaya, Malang, East Java, Indonesia. \\ ${ }^{5}$ Department of Clinical Pathology, Faculty of Medicine, Brawijaya University, Malang, Indonesia.
}

\section{ARTICLE INFO \\ Article history: \\ Received on: $22 / 04 / 2018$ \\ Accepted on: 09/06/2018 \\ Available online: $30 / 07 / 2018$}

Key words:

Apoptosis, 5-FU, Mango

mistletoe (Dendrophthoe

pentandra), p21, survivin.

\begin{abstract}
Mango mistletoe (Dendrophthoe pentandra L. Miq) (MMDP) leaf extract which contained quercetin inhibits cancer cells. MMDP increasing effectively of 5-Fluorouracil (5-FU) as a chemotherapy agent. This study aimed to investigate the synergistic effects of MMDP combined with 5-FU to determine the percentage of apoptosis, p21, and survivin in HeLa cells. Flow cytometry analysis revealed that it increases apoptosis HeLa cell through increasing p21 and also decreased survivin percentage. The combination of 5 -FU $5 \mu \mathrm{g} / \mathrm{ml}$ and MMDP $50 \mu \mathrm{g} / \mathrm{ml}$ significantly increased the percentage of $\mathrm{p} 21$ and apoptosis $(P<0.001 ; P<0.001)$ and decreased survivin $(P<0.05)$ compared with 5 -FU only group. This study indicates that the combined 5-FU and MMDP has a synergistic effect to enhance apoptosis and p21 expressions by decreasing of survivin in HeLa cells.
\end{abstract}

\section{INTRODUCTION}

Cervical cancer is the second most frequently diagnosed malignancy and one of the major causes of death in women worldwide (Tsai et al., 2012). In 2015, it has been reported that 526000 women suffered from cervical cancer, and 239000 was caused by cancer deaths for women (Kashafi et al., 2017). The occurrence of cancer is characterized by uncontrolled cell proliferation.

Human Papilloma Virus (HPV) 16 and 18 are two oncogenes responsible for $70-80 \%$ of all cervical cancer cases worldwide (Jaspers et al., 2011). This has been proven by

"Corresponding Author

Agustina Tri Endharti, Department of Parasitology, Faculty of

Medicine, Brawijaya University, Malang, Indonesia.

E-mail: tinapermana@yahoo.com; tinapermana.fk@ub.ac.id detection of HPV-18 expression and decreased expression of $\mathrm{p} 53$ in HeLa cells. Furthermore, there is evidence that p53 can induce apoptosis and cell cycle arrest can lead to cancer. P21 appears to play also a critical role in apoptosis, as this oncogene switches the p53-dependent response to DNA damage from a cancer cell. Several studies have shown that $\mathrm{p} 21$ induces pro-apoptotic signaling (Zang et al., 2016; Endharti et al., 2017a).

Cancer, in general, occurs because of the inhibition of apoptosis and cell cycle arrest, which is also observed in cervical cancer. The regulation of apoptosis is influenced by $\mathrm{p} 21$. The promotion of the apoptosis mechanism and decrease in p21 expression results in increased apoptosis of cancer cells. The inhibition of apoptosis is regulated by various factors, one of which is the presence of the apoptosis-inhibiting protein, survivin (Jaiswal et al., 2015; Karimian et al., 2016; Endharti et al., 2017b). 
In HeLa cells, an increase in survivin mRNA expression is observed in the G2/M phase, and decreased expression of p21 results in disruption of the cell cycle, thus, inhibit apoptosis of cancer cells ( $\mathrm{Li}$ et al., 2015). Due to the important roles that $\mathrm{p} 21$ and survivin play in cancer development, they were good targets for anti-cancer treatment used to suppress the growth of cancer cells; (Hsieh et al., 2014). p21 binding Nuclear Factor-kappa $\beta(\mathrm{NF}-\mathrm{k} \beta)$ and Signal Transducer and Activator of Transcription (STAT) inhibit a family of antiapoptosis $\mathrm{X}$-Linked Inhibitor Of Apoptosis (XIAP) including survivin occurs apoptosis (Karimian et al., 2016).

One therapeutic agent, adjuvant 5-FU presents side-effects such as neutropenia, stomatitis, diarrhea, and cardiotoxicity (Ciccolini et al., 2010). The active metabolites of 5-FU can inhibit the activity of thymidylate synthase (Chua et al., 2010). Increasing the activity of 5-FU by combination treatment with natural materials is an important way to investigate for the treatment of cervical cancer. A combination treatment of 5-FU and a natural material could increase the sensitivity of cancer cells by enhancing apoptosis (Redondo-Blanco et al., 2017).

Extracts of traditional medicines act as chemosensitizers that made cancer cells more sensitive to the effects of chemotherapeutic agents (Kong et al., 2015; Syakibaei et al., 2013; Xavier et al., 2011). MMDP had a potential for use as an anti-cancer agent because it contained quercetin (Endharti et al., 2016). However, the functional role of $\mathrm{p} 21$ in the induction of $\mathrm{G} 1$ cell cycle arrest and apoptosis by MMDP has not been critically addressed. Previously study has been revealed that quercetin inhibited proliferation of HeLa cells and induced apoptosis by mitochondria pathway (Merino et al., 2014). Recently, conventional chemotherapy is combined with alternative medicines have anticancer potentials and reduce side-effects of chemotherapy (Hemaiswarya and Doble, 2013).

Combination therapy of 5-FU and MMDP have different approaches for the discovery of novel and potential therapeutic agents, medicinal plants are still one of the best reservoirs for new therapy. However, whether these combination therapies exert antitumor activity against colon cancer is not yet clear. In this study, we presented the evidence of MMDP exhibits antitumor activities in vitro. Based on the antitumor effect of MMDP, our study examined the therapeutic potential of MMDP in inhibition of cervical cancer.

\section{MATERIALS AND METHODS}

\section{Cell cultures and treatment}

HeLa Cell Lines was cultured in complete medium Roswell Park Memorial Institute 1640 (RPMI 1640) (Gibco, USA) supplemented with 10\% Fetal Bovine Serum (FBS) (Atlas Biologicals, Fort Collins, CO, USA) solution containing $100 \mathrm{U} /$ $\mathrm{ml}$ Penicillin and $100 \mathrm{U} / \mathrm{ml}$ Streptomycin (Gibco, USA). The cells were kept in a humidified atmosphere of $5 \% \mathrm{CO}_{2}$ at $37^{\circ} \mathrm{C}$ in an incubator. HeLa cells were seeded in 24 -well plate $\left(5 \times 10^{5}\right.$ cell $/ \mathrm{ml})$. The cells were treated with single therapy of 5-FU or combined with a various dose of $\operatorname{MMDP}(12.5,25$ and $50 \mu \mathrm{g} / \mathrm{ml})$, incubated for 24 hours.

\section{Plant material and extraction}

The mango mistletoe extract was utilized in a form of a paste. Mango mistletoe leaves were obtained from a mango farm in
Probolinggo Regency, East Java, Indonesia. The mango mistletoe plant was identified and validated by a botanical biologist at the Faculty of Biology, University of Brawijaya (specimen No.0170/ Taxonomy Identification/03/2015). The extraction method was done according to Endharti et al. (2016).

\section{Analysis of apoptosis}

Cells $\left(1 \times 10^{5}\right)$ were treated with 5-FU and MMDP after 24 hours of incubation. Following centrifugation, cells were processed for apoptosis detection using the Annexin V-FITC Apoptosis Detection Kit (e-Bioscience cat/300) as indicated by the manufacturer. Cells were incubated for 10 minutes with the Annexin V-FICT and further incubated for $5 \mathrm{~min}$ with propidium iodide (Sigma, Kawasaki, Japan) at $4^{\circ} \mathrm{C}$. Cells were analyzed by flow cytometry using the BD FACS Calibur (Becton Dickinson, CA, USA). The percentage of apoptosis cells were quantified by Cell Quest-Pro (Becton Dickinson, USA).

\section{Survivin and p21 analysis}

The pellets were derived from cell culture, then cells were resuspended in Fixating Buffer (Biolegend, San Diego, California, USA) incubated at $4{ }^{\circ} \mathrm{C}$ for 30 minutes. The pellets were incubated in Survivin Antibody (D-8) sc-17779 conjugated with FITC (Santa Cruz Biotechnology, Germany) or p21 antibody (F-5) sc-6246 mouse monoclonal conjugated with FITC (Santa Cruz Biotechnology, Germany) then were incubated for 20 minutes. Samples were immediately analyzed by flow cytometer and the data were analyzed with FACS Calibur Cell Quest-Pro (Becton Dickinson, San Jose, CA, USA).

\section{Statistical analysis}

The relative numbers of all parameters were analyzed using BD CellQuest software. All data were statistically analyzed using an independent t-test in SPSS version 18.

\section{RESULTS AND DISCUSSION}

\section{Results}

Synergistically of MMDP and 5-FU induced apoptosis

The increase of apoptosis percentage from the combined 5-FU and MMDP in different concentration $(12.5,25,50 \mu \mathrm{g} / \mathrm{ml})$ to HeLa cell was evaluated using Annexin V/propidium iodide (PI) (Figure 1A). This results indicated that the combined therapy significantly increases apoptosis percentage, $(P<0.001)$ (Figure 1B). Combination therapy of 5-FU and MMDP had a synergistic increase of apoptosis in HeLa cell line across the broad range of fraction affected.

The combination of MMDP and 5-FU increased p21 of HeLa cell

In this study, the percentage of p21 was observed using flow cytometry to determine the effect of 5-FU and MMDP on increasing percentage of p21 in HeLa cell. Our results showed the percentage of p21 significantly increased in almost all doses of MMDP $(P<0.001$ (Figure 2A). The percentage of p21 were significantly higher in the combination of 5-FU and MMDP $50 \mu \mathrm{g} / \mathrm{ml}$ than $25 \mu \mathrm{g} / \mathrm{ml}$ treatment. The percentage of $\mathrm{p} 21$ increased in a dose-dependent manner (Figure 2B). This finding indicates that combination of 5-FU and MMDP suppressed carcinogenesis by increasing of $\mathrm{p} 21$ in HeLa cells. 
$1 \mathrm{~A}$
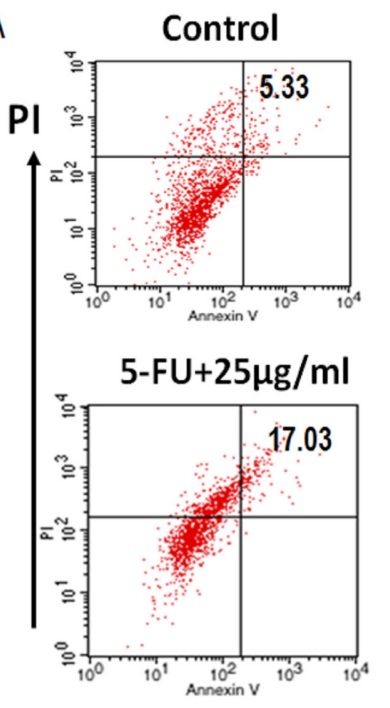
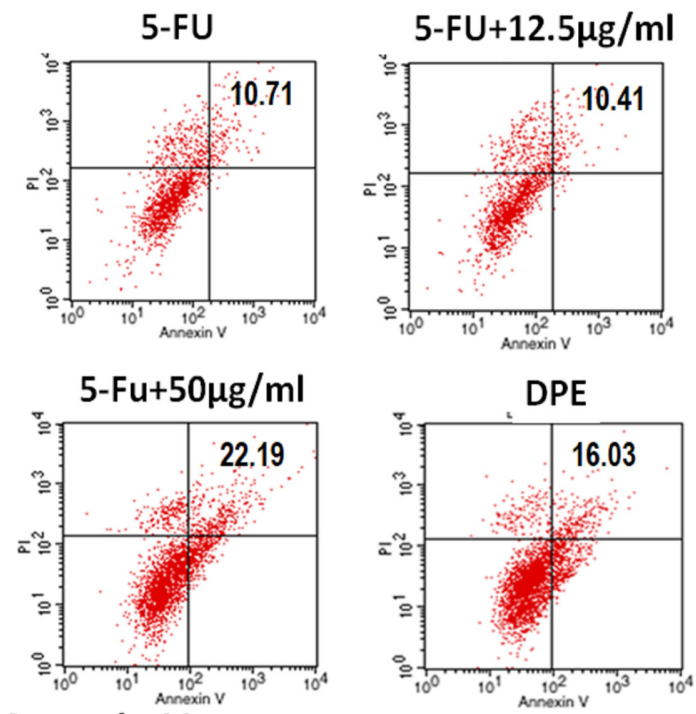

Annexin V

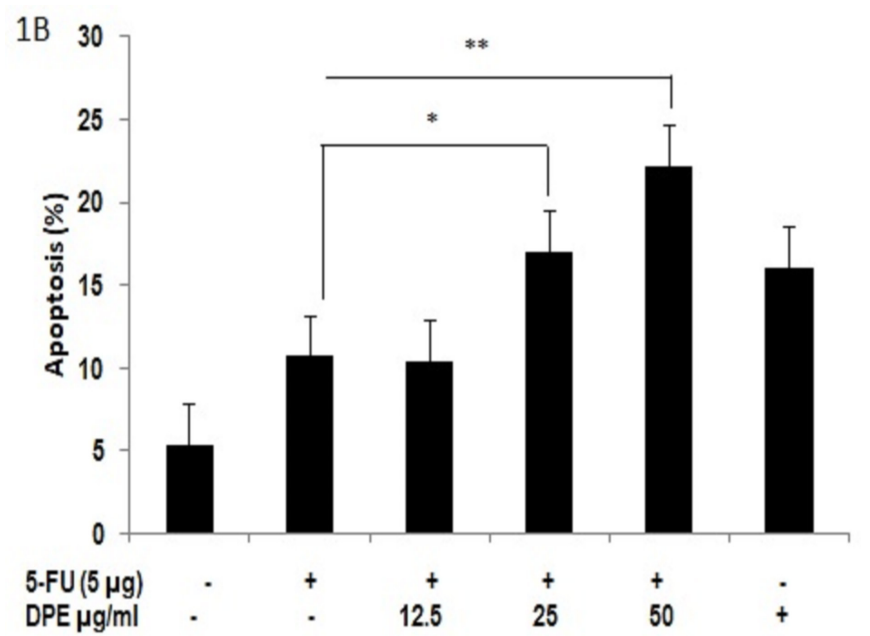

Fig. 1: Induce apoptosis of 5-fluorouracil with or without MMDP on the growth of HeLa cells. The effect of the combined 5-FU + MMDP to the apoptosis on HeLa cells were treated with 5-FU and 12.5, 25, $50 \mu \mathrm{g} / \mathrm{ml}$ MMDP was added for another 24 hours. (A) The percentage of Annexin-V-FITC cells were analyzed using a FACS Calibur flow cytometer (BD Biosciences). Representative results of four replicates in each group are shown. (B) Combination 5-FU and MMDP concentration increased the percentage of apoptosis in HeLa cells. Results shown are mean $\pm \mathrm{SD}$, with $\mathrm{n}=4$ replicates in each group. ${ }^{*} P<0.05, P<0.001$ versus control 5-FU only group.

\section{$M M D P$ reduce survivin in combination with 5-FU}

In this study, survivin was decreased after treatment with 5-FU, MMDP or combination 5-FU and MMDP (Figure 3). The result showed in the combination therapy group with a dose of extract of $50 \mu \mathrm{g} / \mathrm{ml}$ more decreased survivin percentage to other groups, while the untreated group showed the highest percentage of survivin. The only extracted group of $50 \mu \mathrm{g} / \mathrm{ml}$ showed no significant difference with the combination group of $25 \mu \mathrm{g} / \mathrm{ml}$ extract.

\section{Discussion}

Apoptosis occurred as a result of irreparable or incompletely repaired genomic DNA, preventing the proliferation of cells and the development of cancer, thus inducing apoptosis is one approach for the treatment of cancer in addition to conventional treatments such as radiotherapy and chemotherapy (Rebecca, 2011; Hasan et al., 2014).

Our results showed that 5-FU enhanced apoptosis on HeLa cells when combined with MMDP. The mechanism of both 5-FU and MMDP have a different target of action to induce apoptosis in the cell cycle. 5-FU works in G1/S phase whereas MMDP in G2/M phase. Intrinsic pathway increases the permeability of membrane causing cytochrome $\mathrm{C}$ released from mitochondria. Our findings consistent with Priyadarsini et al. (2010) that 5-FU works by causing the G1/S arrest and induces apoptosis by inhibiting the biosynthesis process. MMDP containing quercetin suppresses the viability of HeLa cells in G2/M phase and induces apoptosis through mitochondrial pathways (Priyadarsini et al., 2010; Dun et al., 2015). 

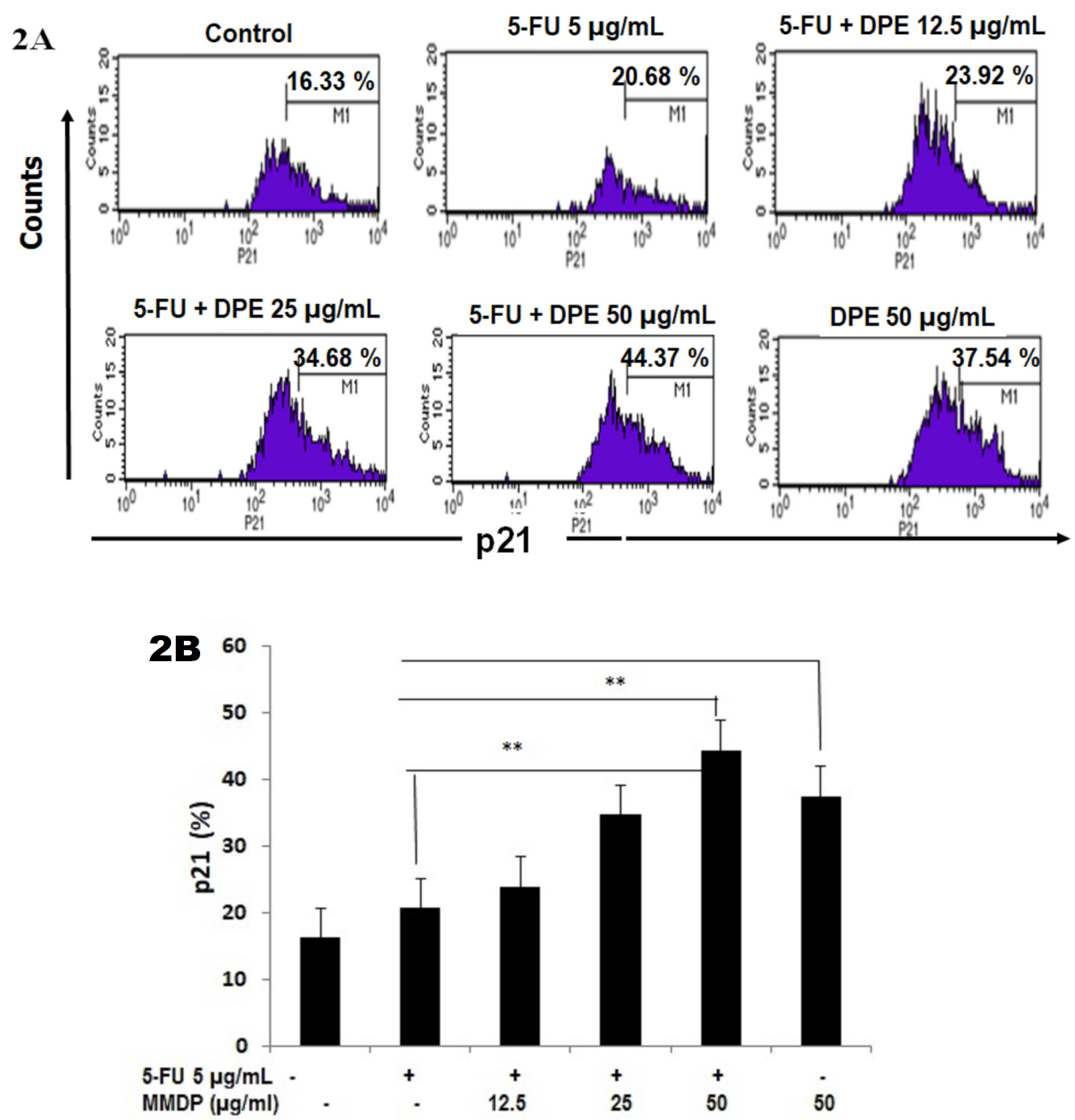

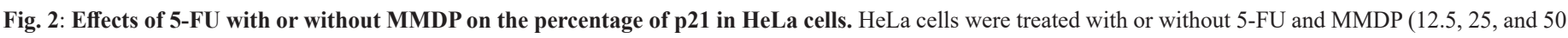

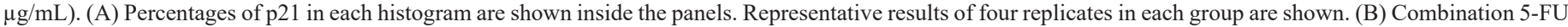

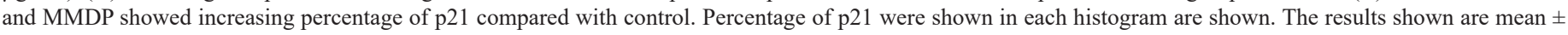
$\mathrm{SD}$, with $\mathrm{n}=4$ replicates in each group. ${ }^{*} P<0.05, P<0.001$ versus control 5-FU group.

The presence of p21 interferes with CDK-cyclin interactions, thereby, inhibiting progression of the cell cycle (Wang et al., 2011). A previous study showed that the MMDP containing quercetin has a potential anti-cancer agent (Endharti et al., 2016). Plant parasites that contain compounds of bioactive treatment, repaired DNA damage by increasing percentage of p21 in HeLa cells (Parwati et al., 2015). Moreover, combination therapy of 5-FU and $50 \mu \mathrm{g} / \mathrm{ml}$ MMDP shown a higher percentage of p21 than MMDP alone. Quercetin may increase the efficacy of 5-FU in human cancer cells (Xavier et al., 2011).

Survivin is an apoptosis inhibitor protein that plays an important role in cancer cell division. Liu et al. (2015) suggested that survivin expression significantly increased in squamous cell carcinoma and adenocarcinoma. 5-FU decreased the expression of survivin but to a lesser extent than the combination therapy. MMDP has many benefits in the treatment of various diseases because it contains secondary metabolite compounds, such as quercetin. Quercetin may induce cancer cell death by mediating the expression of the apoptosis receptors and activity (Xavier et al., 2011; Fitrilia et al., 2015; Wang et al., 2016) and survivin expression (Han et al., 2016).

5-FU rapidly enters into the cell via the uracil transport mechanism and is converted intra-cellularly into three active metabolites to inhibit thymidylate synthase could break DNA synthesis. DNA damage in cancer cells results in the induction of apoptosis through the activation of p53, modulation of the permeability of the mitochondrial membrane, and suppression of survivin expression (Srivastava et al., 2016). Quercetin induced apoptosis by PI3K/Akt pathway (Kashafi et al., 2017). The role of p21 in biological processes, such as DNA repair, remains controversial. In addition, p21 act as a proapoptosis if binding with NF-k $\beta$ and STAT so that it can inhibit survivin thus induce apoptosis. Akt is an antiapoptosis protein phosphorylating p21 occurs binding of p21 with PCNA could disruption induced checkpoint causes DNA repair or induced apoptosis (Karimian et al., 2016). 
$3 \mathbf{A}$

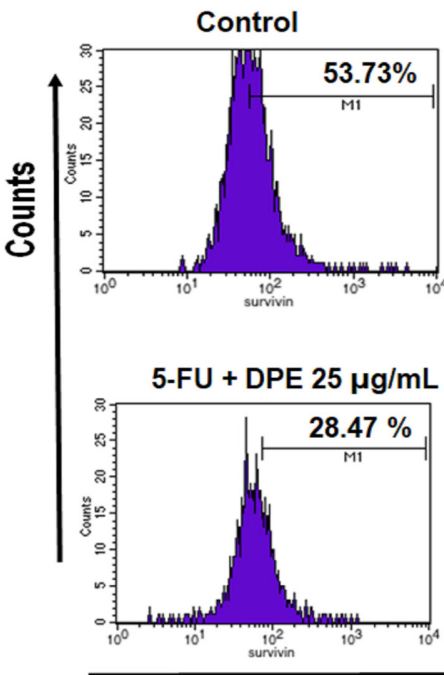

5-FU $5 \mu \mathrm{g} / \mathrm{mL}$

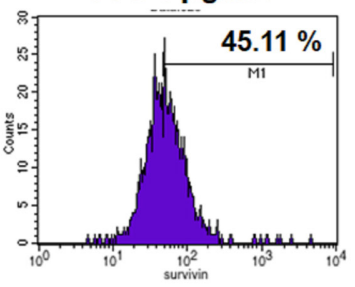

$5-F U$ + DPE $50 \mu \mathrm{g} / \mathrm{mL}$

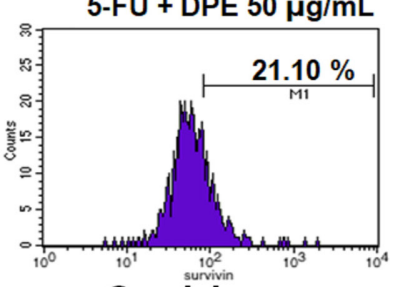

Survivin
5-FU + DPE $12.5 \mu \mathrm{g} / \mathrm{mL}$

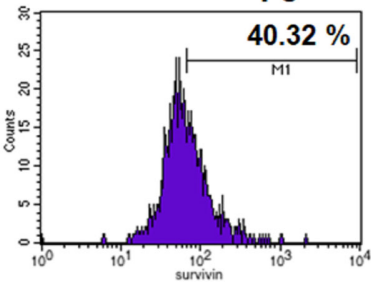

DPE $50 \mu \mathrm{g} / \mathrm{mL}$

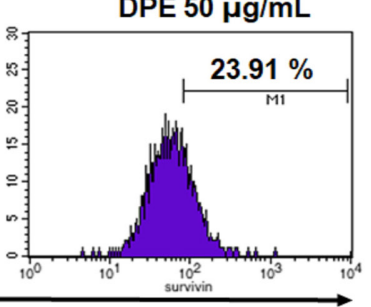

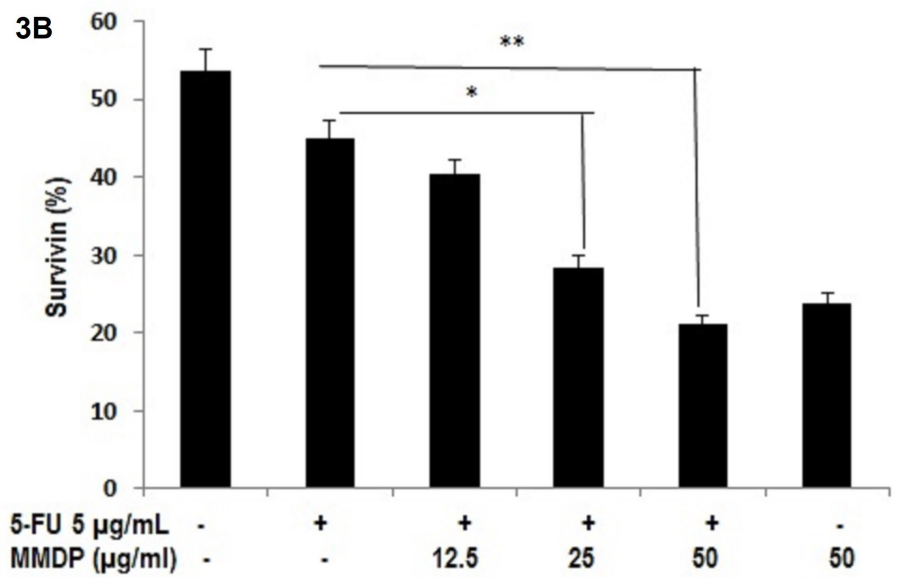

Fig. 3: Effects of 5-FU with or without MMDP on the percentage of survivin in HeLa cells. HeLa cells were treated with or without 5-FU and MMDP (12.5, 25, and $50 \mu \mathrm{g} / \mathrm{mL}$ ). (A) Percentages of survivin in each histogram are shown inside the panels. Representative results of four replicates in each group are shown. (B) Combination 5-FU and MMDP showed increasing percentage of survivin compared with control. Percentage of survivin were shown in each histogram are shown. The results shown are mean $\pm \mathrm{SD}$, with $\mathrm{n}=4$ replicates in each group. ${ }^{*} P<0.05, P<0.001$ versus control 5 -FU group.

The mechanism of action of MMDP is similar to that of 5-FU, as it intercalates in cancer cell DNA, causing DNA damage and increased activation of the $\mathrm{p} 53$-induced apoptosis pathway; this activation suppresses the expression of survivin. In this study, combination therapy most significantly decreased the expression of survivin, however MMDP when administered singly effectively decreased the expression of survivin. This study supports the previous study that combination therapy with 5-FU and the other agent significantly decreases the expression of survivin (Liang et al., 2013).

\section{CONCLUSIONS}

The study showed that the combination of 5-FU and MMDP able to increase the number of apoptosis cells, p21 expression and reduce survivin expression of HeLa cells. Our results highlight the new therapeutic concept which combines chemotherapy agents of 5-FU and MMDP in treating cervical cancer.

\section{CONFLICTS OF INTEREST}

The authors declare that there is no conflict of interest regarding the publication of this paper.

\section{ACKNOWLEDGMENTS}

We gratefully acknowledge Heni Endrawati, SSi and Bunga Prihardina, SSi for technical assistance.

\section{REFERENCES}

Chua W, Kho PS, Moore MM, Charles KA, Clarke SJ. Clinical, laboratory and molecular factors predicting chemotherapy efficacy and toxicity in colorectal cancer. Crit Rev Oncol Hematol, 2010; In press.

Ciccolini J, Gross E, Dahan L, Lacarelle B, Mercier C. Routine dihydropyrimidine dehydrogenase testing for anticipating 5-fluorouracilrelated severe toxicities hype or hope?. Clin Colorectal Cancer, 2010; 9(4):224-8.

Dun J, Chen X, Gao H, Zhang Y, Zhang H, Zhang Y. Resveratrol synergistically augments anti-tumor effect of 5-FU in vitro and in vivo by increasing S-phase arrest and tumor apoptosis. Experimental Biology and Medicine, 2015; 240(12):1672-81. 
Endharti AT, Wulandari A, Lisyana A, Norahmawati E, Permana S. Dendrophthoe pentandra (L.) Miq extract effectively inhibits inflammation, proliferation and induces p21 expression on colitisassociated colon cancer. BMC Complementary and Alternative Medicine, 2016; 16:374.

Endharti AT, Baskoro AD, Norahmawati E, Therapeutic effect of soluble worm protein acting as immune regulatory on colitis. Asian Pac J Trop Biomed, 2017a; 7(1):70-77.

Endharti AT, Permana S. Extract from mango mistletoes Dendrophthoe pentandra ameliorates TNBS induced colitis by regulating $\mathrm{CD} 4+\mathrm{T}$ cells in mesenteric lymph nodes. BMC Complementary and Alternative Medicine, 2017b; 17:468.

Fitrilia L, Bintang M, Safithri M. Phytochemical Screening and Antioxidant Activity of Clove Mistletoe Leaf Extracts (Dendrophthoe pentandra (L.) Miq). IOSR Journal Of Pharmacy, 2015; 5:13-8.

Han C, Gao H, Zhang X. The anti-cancer effect of Quercetin in renal cancer through regulating survivin expression and caspase 3 activity. Med One, 2016; 1-8.

Hassan M, Watari H, Almaaty, Ohba Y, Sakuragi N. Apoptosis and molecular targeting therapy in cancer. BioMed Research International, 2014; 1-24.

Hemaiswarya S, Doble M. Combination of phenylpropanoids with 5-fluorouracil as anti-cancer agents against human cervical cancer (HeLa) cell line. Phytomedicine, 2013; 20:151-158.

Hsieh YJ, Hwu I, Chen YC, Ke CC, Chen FD, Wang HE, et al. P21-driven multifusion gene system for evaluating the efficacy of histone deacetylase inhibitors by in vivomolecular imaging and for transcription targeting therapy of cancer mediated by histone deacetylase inhibitor. J Nucl Med, 2014; 55.

Hydbring P, Malumbres M, Sicinski P. Non-canonical functions of cell cycle cyclins and cyclin-dependents kinases. Nat Rev Moll Cell Biol, 2016; 17:280-292.

Jaiswal PKA, Goel, Mittal RD. Survivin: A Molecular Biomarker in Cancer. Indian J Med Res, 2015; 141(4):387-397.

Jaspers L, Budiningsih S, Wolterbeek R, Henderson F, Peters A. Parental acceptance of human papillomavirus (HPV) vaccination in Indonesia: A cross-sectional study. Vaccine, 2011; 29:7785-7793.

Tsai SJ, Hwang JM, Hsieh SC, Ying TH, Hsieh Y. Overexpression of myeloid zinc finger 1 suppresses matrix metalloproteinase-2 expression and reduces invasiveness of $\mathrm{SiHa}$ human cervical cancer cells. Biochemical and Biophysical Research Communications, 2012; 425:462-467.

Karimian A, Ahmadi Y, Yousefi B. Multiple function of p21 in cell cycle, apoptosis and transcriptional regulation after DNA damage. DNA Repair, 2016; 42:63-71.

Kashafi E, Moradzadeh M, Mohamadkhani A, Erfanian S. Kaempferol Increases Apoptosis in Human Cervical Cancer HeLa Cells via PI3K/AKT and Telomerase Pathways. Biomedicine \& Pharmacotherapy, 2017; 89:573-577.

Kong L, Wang X, Zhang K, Yuan W, Yang Q, Fan J, et al. Gypenosides sinergistically enhances the anti-tumor effect of 5-fluorouracil on colorectal cancer in vitro and in vivo: a role for oxidative stress-mediated DNA damage and $\mathrm{p} 53$ activation. Plos One, 2015; 14:1-17.

Li Y, Liu D, Zou Y, Xie J, Lee RJ, et al. Silencing of Survivin Expression Leads to Reduced Proliferation and cell cycle Arrest in Cancer cells. Journal of Cancer, 2015; 6:1187-1194.
Liang S-R, Hui G-R, Huang S-J, Li J-S, Zhao M-Y, et al. CpG Oligodeuoxynucleotides Enhance Chemosensitivity of 5-Fluorouracil in Hepg2 Human Hepatome Cells via Downregulation of the Antiapoptotic Factors Survivin and Livin, Cancer Cell International, 2013; 13:1-10.

Merino JM, Paredes AC, Ulloa EV, Zavaleta LR, Gonzalez AMF, Lizano M. The role of signaling pathways in cervical cancer and molecular therapeutic targets. Archives of Medical Research, 2014; 45:525-539.

Parwati NWMP, Lindayani IK, Ratnawati R, Winarsih S, Nurseta T. Possible effect of tea plant parasite, Scurrula atropurpurea (Blume) danser, on growth inhibition of culture HeLa cells in vitro through DNA repai and apoptosis intrinsic pathways mechanism. Asian Pasific of Tropical Disease, 2015; 5:743-746.

Pavlides SC, Lecanda J, Daubriac J, Pandya UM, Gama P, Blank S. TGF- $\beta$ activates APC through cdh 1 binding for cks 1 and skp 2 proteasomal destriction stabilizing p27 kip 1 for normal endometrial growth. Journal cell cycle, 2016; 15(7):931-47.

Priyadarsini RV, Murungan RS, Maitreyi S, Ramalingan K, Karunagaran DB, Nagini S. The flavonoid quercetin induces cell cycle arrest and mitochondria-mediated apoptosis in human cervical cancer (HeLa) cells through p53 induction and NF- $\mathrm{kB}$ inhibition. European Journal of Pharmacology, 2010; 649:84-91.

Rebecca SYW. Apoptosis in cancer: from pathogenesis to treatment. Journal of experimental \& clinical cancer research, 2011; 30(87).

Redondo-Blanco S, Fernández J, Gutiérrez-del-Río I, Villar CJ, Lombó F. New Insights toward Colorectal Cancer Chemotherapy Using Natural Bioactive Compounds. Front Pharmacol, 2017; 8:109.

Srivastava S, Somasagara RR, Hegde M, Nishana M, Tadi ST, Srivastava M, et al. Quercetin, a Natural Flavonoid Interacts with DNA, Arrests Cell Cycle and Causes Tumor Regression by Activating Mitochondrial Pathway of Apoptosis. Scientific reports, 2016; 6:1-13.

Syakibaei M, Mobasheri A, Lueders C, Busch F, Shayan P, Goel A. Curcumin enhances the effect of chemotherapy against colorectal cancer cell by inhibition of NF- $\mathrm{k} \beta$ and Src protein kinase signaling pathways. Plos One, 2013; 8(2):1-13.

Wang W, Sun C, Mao L, Ma P, Liu F, Yang J, et al. The Biological Activities, Chemical Stability, Metabolism and Delivery Systems of quercetin: a Review. Trends in Food Science \& Technology, 2016; 56:21-38.

Wang Y, Fisher JC, Mathew R, Ou I, Otieno S, Subiet J, et al. Intrinsic disorder mediates the diverse regulatory function of the $\mathrm{Cdk}$ inhibitor p21. Nat Chem Biol, 2011; 7:214-221.

Xavier CPR, Lima CF, Rohde M, Wilson CP. Quercetin enhance 5-Flourouracil-induced apoptosis in MSI colorectal cancer cell through p53 modulation. Cancer Chemother Pharmacol, 2011; 68:1449-1457.

Zhang X, Song X, Yin S, Zhao C, Fan L, Hu H. p21 induction plays a dual role in anti-cancer activity of ursolic acid. Exp Biol Med, 2016; 241(5):501-508.

How to cite this article:

Endharti AT, Sulastri E, Umanailo R, Yunialce, Nurseta $\mathrm{T}$, Handono K. Mango mistletoe Dendrophthoe pentandra leaf extract acts synergistically with 5-Fluorouracil to induce apoptosis and increase p21 expression in human cervical adenocarcinoma HeLa cells by reducing survivin expression. J App Pharm Sci, 2018; 8(07): 010-015. 